\title{
PENGARUH VARIASI KONSENTRASI GELLING AGENT CARBOPOL 940 TERHADAP SIFAT FISIK SEDIAAN GEL HAND SANITIZER MINYAK ATSIRI DAUN KEMANGI
} (Ocimum Sanctum L.)

${ }^{1}$ Iin Lidia Putama Mursal, ${ }^{2}$ Anggun Hari Kusumawati, ${ }^{3}$ Devi Hartianti Puspasari ${ }^{1}$ Prodi Farmasi Fakultas Teknologi dan Ilmu Komputer Universitas Buana Perjuangan Karawang (iin.lidia@ubpkarawang.ac.id)

${ }^{2}$ Prodi Farmasi Fakultas Teknologi dan Ilmu Komputer Universitas Buana Perjuangan Karawang (anggunhari@ubpkarawang.ac.id)

${ }^{3}$ Prodi Farmasi Fakultas Teknologi dan Ilmu Komputer Universitas Buana Perjuangan Karawang (fm15.devipuspasari@mhs.ubpkarawang.ac.id)

\begin{abstract}
ABSTRAK
Hand sanitizer adalah produk efektif dan murah yang dapat mengurangi mikroorganisme pada kulit. Banyak hand sanitizer yang mengandung etanol dan alkohol dengan kadar $60 \%-95 \%$ tetapi kandungan alkohol dalam hand sanitizer dapat menyebabkan resiko kesehatan. Penelitian ini bertujuan untuk melihat pengaruh gelling agent Carbopol 940 terhadap sifat fisik sediaan gel hand sanitizer. Konsentrasi yang digunakan untuk gelling agent Carbopol 940 yaitu 0,5\%; 1\%; 1,5\%. Uji sifat fisik meliputi uji organoleptik, uji homogenitas, uji $\mathrm{pH}$, uji viskositas, uji daya sebar dan uji daya lekat. Hasil penelitian sifat fisik sediaan gel hand sanitizer minyak atsiri daun kemangi yaitu peningkatan kadar gelling agent menyebabkan warna gel semakin pudar, wujud semakin kental, peningkatan viskositas, peningkatan daya lekat dan penurunan daya sebar. Berdasarkan uji sifat fisik sediaan gel hand sanitizer minyak atsiri daun kemangi dapat disimpulkan bahwa (F2) dengan konsentrasi 1\% Carbopol 940 adalah formula optimal karena memenuhi semua persyaratan sifat fisik gel.
\end{abstract}

Kata kunci : gelling agent, carbopol 940, sifat fisik, Ocimum sanctum L.

\begin{abstract}
Hand sanitizers were effective and inexpensive product that can reduce of microorganims on the skin. Many hand sanitizer have contents up to 60\%-95\% ethanol and isopropyl alcohol, but using alcohol in hand sanitizer can cause health risks effect. The aim of this work was to determine the effects of gelling agent Carbopol 940 on physical properties of formulation gel hand sanitizer. The concentration that used for the Carbopol 940 gelling agent are 0,5\%; 1\%; 1,5\%. The test of physical properties includes organoleptic, homogeneity, $\mathrm{pH}$, viscosity, dispersive ability, and adhesion The results of this research on the physical properties gel hand sanitizer of basil essensial oil, showed that the increasing of gelling agent consentrasion, makes the gel getting faded, more thicker, increase of viscosity, adhesion and decrease of dispersive ability. Based on the physical properties test, (F2) with 1\% concentration of Carbopol 940 is the optimal formula it caused by it suitable all the parameters of the physical properties of gel.
\end{abstract}

Keywords : gelling agent, carbopol 940, physical properties, Ocimum sanctum L. 


\section{PENDAHULUAN}

Hand sanitizer merupakan jenis cairan pembersih tangan yang berbahan dasar alkohol yang digunakan untuk membunuh mikroorganisme dengan pemakaian tanpa dibilas air (Larasati, D.A \& Ety, A., 2016). Komponen utama kemangi yaitu minyak atsiri yang dapat berfungsi sebagai antibakteri. Minyak atsiri dalam kemangi dapat digunakan sebagai pengganti alkohol dalam sediaan gel hand sanitizer. Produk hand sanitizer yang beredar di pasar rata-rata dalam bentuk sediaan gel. Gel mempunyai potensi lebih baik sebagai sarana untuk mengelola obat topikal dibandingkan dengan salep, karena gel tidak lengket, memerlukan energi yang tidak besar untuk formulasi, stabil, dan mempunyai estetika yang bagus (Ardana et al., 2015). Selain itu, gel dapat menghantarkan bahan obat dengan baik. Keuntungan lain sediaan gel antara lain mudah merata apabila dioleskan pada kulit, memberikan sensasi dingin, dan tidak menimbulkan bekas di kulit (Afianti, H.F \& Mimiek M., 2015).

Pada formulasi sediaan gel, gelling agent merupakan faktor kritis yang berpengaruh terhadap sifat fisik sediaan gel yang dihasilkan. Salah satu gelling agent yang dapat digunakan yaitu Carbopol 940. Carbopol 940 lebih dikenal dengan nama karbomer 940 merupakan basis gel yang bersifat mudah terdispersi dalam air dan memberikan kekentalan atau kekerasan pada sediaan gel (Saryanti \& Izzatun., 2017). Basis gel carbopol bila diformulasikan akan membentuk gel dengan penampakan yang jernih, mempunyai daya sebar yang baik pada kulit, efeknya mendinginkan, tidak menyumbat pori-pori kulit, dan mudah dicuci dengan air (Su'aida et al., 2017). Keuntungan lainnya dengan konsentrasi kecil Carbopol 940 dapat menghasilkan nilai viskositas yang lebih tinggi dibandingkan dengan gelling agent lainnya. Berdasarkan uraian diatas, maka dilakukan penelitian untuk melihat pengaruh variasi konsentrasi gelling agent Carbopol 940 terhadap sifat fisik sediaan gel hand sanitizer minyak atsiri daun kemangi. 


\section{METODE PENELITIAN}

\section{Alat dan Bahan}

Alat-alat yang digunakan yaitu cawan petri, batang pengaduk, spatula, mortir dan stamper, gelas ukur (PYREX), gelas kimia (BONEX), pipet tetes, sendok tanduk, timbangan analitik, kaca arloji, botol kaca selai, viskometer (Lamy Rheology), kaca uji daya sebar, instrumen uji daya lekat dan $\mathrm{pH}$ universal (ph stick Merck).

Bahan-bahan yang digunakan diantaranya minyak atsiri daun kemangi (Ocimum sanctum L.), Carbopol 940, Gliserin 84,5\% (Merck), TEA 99\% (Merck) dan Aquadest.

\section{Pembuatan Gel Antiseptik}

Pada penelitian ini diformulasikan gel hand sanitizer minyak atsiri daun kemangi dengan 3 variasi konsentrasi yaitu $0,5 \%, 1 \%$ dan 1,5\% yang dapat dilihat pada Tabel 1.

Tabel 1. Formulasi Gel Hand Sanitizer Minyak Atsiri Daun Kemangi

\begin{tabular}{lccc}
\hline \multirow{2}{*}{ Bahan } & \multicolumn{2}{c}{ Jumlah (\%) } \\
\cline { 2 - 4 } & F1 & F2 & F3 \\
\hline Minyak Atsiri Daun Kemangi & 1 & 1 & 1 \\
\hline Carbopol & 0,5 & 1 & 1,5 \\
\hline Metil Paraben & 0,18 & 0,18 & 0,18 \\
\hline Propil Paraben & 0,02 & 0,02 & 0,02 \\
\hline Gliserin & 15 & 15 & 15 \\
\hline TEA & 0,5 & 0,5 & 0,5 \\
\hline Aquadest ad (g) & 100 & 100 & 100
\end{tabular}

Sediaan gel dengan gelling agent Carbopol dilarutkan dalam $50 \mathrm{~mL}$ aquadest diamkan sampai mengembang selama 24 jam. Metil paraben dan propil paraben dilarutkan dalam gliserin kemudian tambahkan kedalam larutan carbopol. Minyak atsiri ditambahkan dengan pipet sambil diaduk. Kemudian tambahkan TEA sampai terbentuk gel yang homogen dan tambahkan sisa aquadest. 


\section{Evaluasi Sediaan}

1. Uji Organoleptik

Uji organoleptik yaitu dilakukan secara visual dengan melihat warrna, tekstur dan bau sediaan.

2. Uji Homogenitas

Pengujian homogenitas dilakukan diatas plat kaca. Sediaan dinyatakan homogen jika tidak terdapat butiran kasar pada sediaan

3. Uji pH

Pengujian $\mathrm{pH}$ dilakukan dengan menggunakan kertas $\mathrm{pH}$ universal yang dicelupkan ke dalam sampel, perubahan yang terjadi dicocokan pada standar $\mathrm{pH}$ universal. Berdasakan Badan Standar Nasional (BSNI/BSN/SNI) yaitu pada SNI 16-43801196 untuk pH kulit manusia yaitu 4,6-6,5.

\section{Uji Viskositas}

Uji viskositas pada penelitian ini dilakukan dengan menggunakan viskometer digital (Lamy Rheology). Uji viskositas dilakukan dengan cara sebanyak $100 \mathrm{~mL}$ gel dimasukkan ke dalam wadah berbentuk tabung lalu dipasang spindle.. Kemudian amati hasil viskositas pada layar viskometer.

\section{Uji Daya Sebar}

Uji daya sebar dilakukan dengan menimbang sediaan gel sebanyak 1 gram dan diletakkan pada plat kaca. Kemudian di atas plat kaca tersebut diletakkan plat kaca lain tanpa diberi tekanan, setelah itu diukur diameternya.

\section{Uji Daya Lekat}

Uji daya lekat dilakukan dengan cara 0,25 gram gel diletakkan di atas dua gelas objek yang telah ditentukan, kemudian ditekan dengan beban 500g selama 5 menit. Setelah itu dipasang objek glass pada alat uji lalu ditambahkan beban 65,95 gram pada alat uji, kemudian dicatat waktu pelepasan dari gelas objek. 


\section{PEMBAHASAN}

\section{Uji Organoleptik}

Tujuan uji organoleptis ini untuk mengetahui tampilan gel yang berupa wujud, warna, dan bau sediaan gel. Pengujian ini perlu dilakukan karena berkaitan dengan kenyamanan pemakaian sebagai sediaan topikal (Afianti \& Mimiek, 2015).

Tabel 2. Hasil Pengamatan Organoleptik

\begin{tabular}{|c|c|c|c|c|}
\hline \multirow{2}{*}{ Formula } & \multirow{2}{*}{ Konsentrasi } & \multicolumn{3}{|c|}{ Organoleptis } \\
\hline & & Wujud & Warna & Bau \\
\hline F1 & $0,5 \%$ & $\begin{array}{l}\text { Semisolid } \\
(+++)\end{array}$ & $\begin{array}{l}\text { Kuning } \\
(+++++)\end{array}$ & Khas kemangi \\
\hline F2 & $1 \%$ & $\begin{array}{l}\text { Semidolid } \\
(++++)\end{array}$ & $\begin{array}{c}\text { Kuning } \\
(+++)\end{array}$ & Khas kemangi \\
\hline F3 & $1,5 \%$ & $\begin{array}{c}\text { Semisolid } \\
(+++++)\end{array}$ & $\begin{array}{c}\text { Kuning } \\
(++)\end{array}$ & Khas kemangi \\
\hline
\end{tabular}

\section{Keterangan:}

1. $(+)-(+++++)$ menunjukan bentuk sediaan yang semakin tinggi (kental)

2. $(+++++)-(+)$ menunjukan warna sediaan yang semakin rendah (pudar)

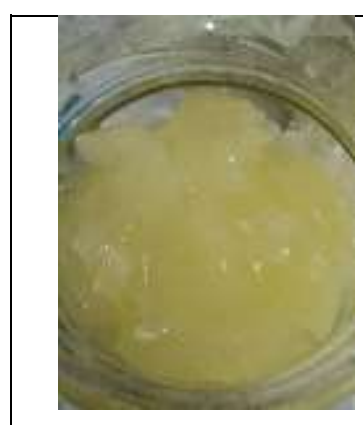

F1

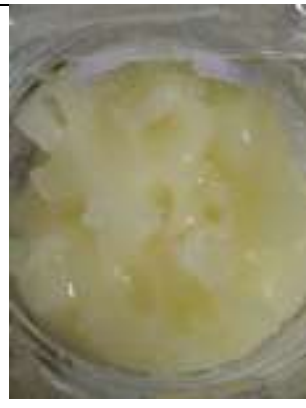

F2

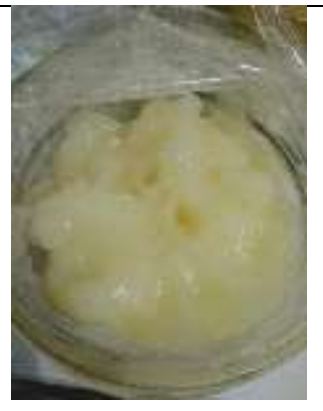

F3

\section{Gambar 1. Sediaan Gel Hand Sanitizer Minyak Atsiri Daun Kemangi}

Berdasarkan hasil pengamatan organoleptik sediaan gel hand sanitizer dengan gelling agent Carbopol 940 menghasilkan wujud yang semakin kental setiap penambahan konsentrasi pada formulasi sediaan. Warna yang dihasilkan sediaan gel hand sanitizer minyak atsiri daun kemangi yaitu berwarna kuning cerah untuk (F1) dan warna semakin pudar setiap penambahan konsentrasi sedangkan untuk bau sediaan (F1), (F2) dan (F3) tidak ada perubahan yaitu tetap berbau khas kemangi. 


\section{Uji Homogenitas}

Uji homogenitas sangat penting dilakukan dalam uji fisik untuk sediaan topikal, tujuan dari uji homogenitas adalah untuk mengetahui apakah bahan-bahan dalam formulasi tersebut tercampur secara merata atau tidak.

Tabel 3. Hasil Pengamatan Homogenitas

\begin{tabular}{ccc}
\hline Formula & Konsentrasi & \multicolumn{1}{c}{ Homogenitas } \\
\hline F1 & $0,5 \%$ & Homogen, tidak terdapat butiran kasar \\
\hline F2 & $1 \%$ & Homogen, tidak terdapat butiran kasar \\
\hline F3 & $1,5 \%$ & Homogen, tidak terdapat butiran kasar \\
\hline
\end{tabular}

Pemeriksaan homogenitas terhadap sediaan gel hand sanitizer minyak atsiri daun kemangi terlihat bahwa pada (F1), (F2) dan (F3) homogen, tidak terdapat butiran kasar pada sediaan. Hal ini sesuai dengan persyaratan homogenitas gel yaitu gel harus menunjukkan susunan yang homogen dan tidak terlihat adanya butiran kasar (Saraung et al, 2018).

\section{Uji pH}

Pengukuran $\mathrm{pH}$ bertujuan untuk mengetahui apakah sediaan dapat diterima oleh kulit atau tidak, diterima disini yaitu sediaan tersebut harus aman saat digunakan pada kulit.

\section{Tabel 4. Hasil Uji pH}

\begin{tabular}{ccc}
\hline Formula & Konsentrasi & Uji pH \\
\hline F1 & $0,5 \%$ & 5 \\
\hline F2 & $1 \%$ & 5 \\
\hline F3 & $1,5 \%$ & 4 \\
\hline
\end{tabular}

Nilai $\mathrm{pH}$ sediaan gel hand sanitizer minyak atsiri daun kemangi dengan gelling agent Carbopol 940 pada konsentrasi 0,5\%; 1\% dan 1,5\% dihasilkan nilai pH 5, 5 dan 4. Perubahan $\mathrm{pH}$ dapat terjadi karena Carbopol 940 memiliki $\mathrm{pH}$ asam yaitu 3 sehingga pada pembuatan formulasi gel dengan gelling agent Carbopol 940 perlu ditambahakan penetralan basa tertentu. Penetralan akan menghasilkan gaya tolak menolak pada gugus $\mathrm{COO}^{-} \mathrm{Carbopol} \mathrm{sehingga} \mathrm{strukturnya} \mathrm{menjadi} \mathrm{lebih} \mathrm{rigid} \mathrm{dan}$ viskositasnya meningkat (Osborne, 1990). TEA dipilih sebagai penetral karena memiliki pH 10,5 dan dapat membantu sebagai penetral Carbopol. pH pada sediaan dipengaruhi oleh konsentrasi Carbopol 940, sehingga semakin tinggi konsentrasi 
Carbopol dan penambahan TEA pada konsentrasi yang sama menyebabkan $\mathrm{pH}$ sediaan gel dengan gelling agent Carbopol 940 menjadi semakin asam.

Pada penelitian ini (F1) dan (F2) termasuk aman karena memiliki pH 5. Hal ini sesuai dengan Badan Standar Nasional (BSNI/BSN/SNI) yaitu pada SNI 16-43801196 untuk pH kulit manusia yaitu 4,6-6,5.

\section{Uji Viskositas}

Pengujian viskositas bertujuan untuk mengukur besarnya nilai viskositas dari sediaan, dimana nilai viskositas merupakan pernyataan tahanan dari suatu cairan untuk mengalir, semakin tinggi viskositas maka semakin tinggi tahanannya (Martin et al, 1993). Semakin tinggi tahanannya maka sediaan tersebut akan semakin kental dan sulit untuk mengalir. Kekentalan gel harus sesuai karena berpengaruh terhadap kenyamanan saat sediaan tersebut diaplikasikan.

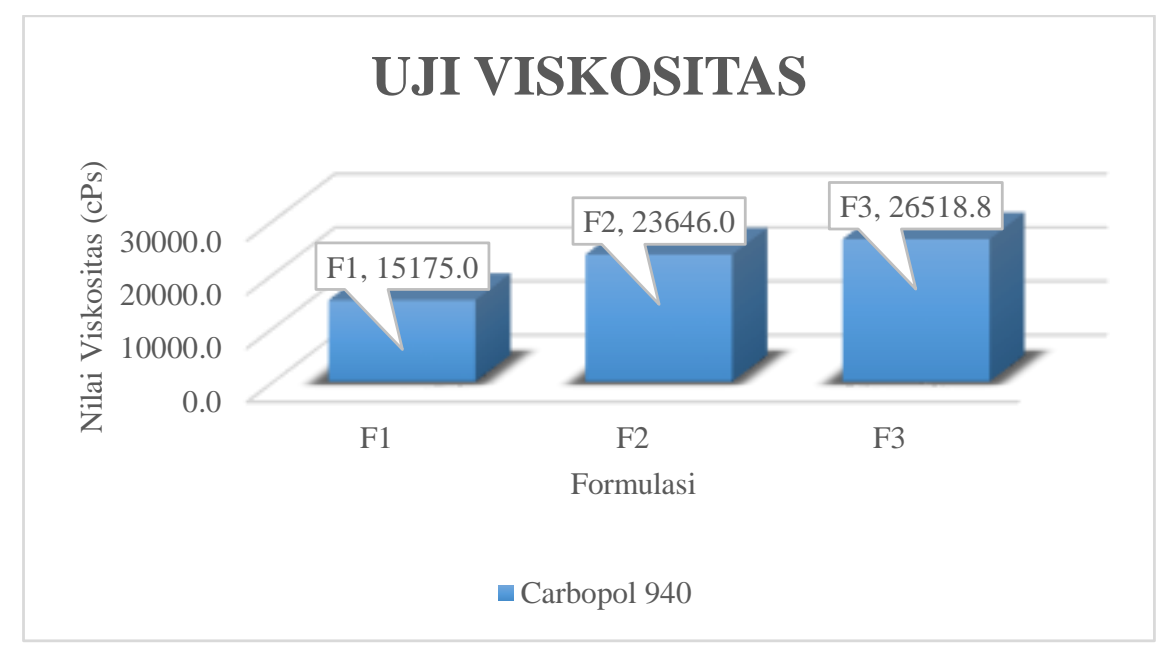

Gambar 2. Hasil Pengujian Viskositas

Perubahan viskositas dipengaruhi oleh konsentrasi gelling agent dapat dilihat pada (Gambar 2) semakin tinggi konsentrasi gelling agent yang digunakan maka semakin semakin tinggi nilai viskositas yang akan dihasilkan karena semakin tinggi konsentrasi gelling agent maka semakin banyak jumlah polimer.

Pada penelitian ini formulasi sediaan gel hand sanitizer minyak atsiri daun kemangi dengan gelling agent Carbopol 940 menghasilkan nilai viskositas yang memenuhi persyaratan sediaan gel. Hal ini sesuai dengan parameter nilai viskositas untuk sediaan gel berdasarkan SNI 16-4380-1996 adalah 3.000 - 50.000 cps. 


\section{Uji Daya Sebar}

Gelling agent sangat mempengaruhi sifat fisik sediaan salah satunya daya sebar. Daya sebar merupakan faktor yang mempengaruhi efikasi terapi topikal pada sediaan farmasi (Baktiman, 2014) dan luas penyebaraan sediaan saat diaplikasikan pada kulit.

Tabel 5. Hasil Uji Daya Sebar

\begin{tabular}{cccc}
\hline \multicolumn{4}{c}{ Uji Daya Sebar $(\mathbf{c m})$} \\
\hline Gelling Agent & Formula & Konsentrasi & Mean \pm SD \\
\hline Carbopol 940 & F1 & $0,5 \%$ & $7,57 \pm 0,16$ \\
\cline { 2 - 4 } & F2 & $1 \%$ & $6,82 \pm 0,35$ \\
\cline { 2 - 4 } & F3 & $1,5 \%$ & $5,74 \pm 0,21$ \\
\hline
\end{tabular}

Pengujian daya sebar sediaan gel hand sanitizer minyak atsiri daun kemangi dengan variasi konsentrasi gelling agent Carbopol 940 menghasilkan nilai daya sebar yang berbeda. Perbedaan daya sebar sangat berpengaruh terhadap kecepatan difusi zat aktif dalam melewati membran, semakin luas membran tempat sediaan menyebar maka koefisien difusi makin besar yang mengakibatkan difusi obat pun semakin meningkat sehingga semakin besar daya sebar suatu sediaan maka semakin baik (Hasyim, 2012). Pada penelitian ini penambahan konsentrasi sangat berpengaruh terhadap nilai daya sebar yang dihasilkan, semakin tinggi konsentrasi maka daya sebar akan semakin kecil, hal ini dikarenakan penambahan konsentrasi menyebabkan matriks yang terbentuk dalam sediaan gel akan semakin rapat. Pada pengujian daya sebar dengan gelling agent Carbopol 940 (F2) dan (F3) termasuk dalam kategori daya sebar yang baik karena memenuhi persyaratan uji daya sebar dimana daya sebar yang nyaman dalam penggunaan untuk sediaan semisolid berkisar 5-7 cm (Garg, 2002).

\section{Uji Daya Lekat}

Pengujian daya lekat untuk mengetahui kemampuan gel saat melekat pada kulit. Semakin melekat gel pada kulit maka zat aktif yang berdifusi pada kulit semakin banyak sehingga gel yang gunakan semakin efektif (Voigt, 1984). 


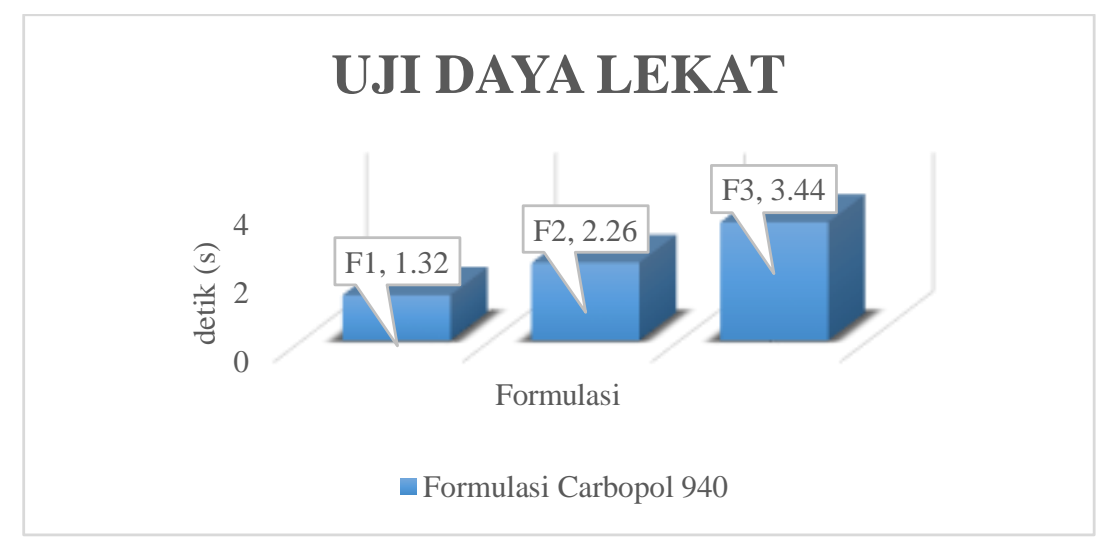

Gambar 3. Hasil Uji Daya Lekat

Peningkatan konsentrasi pada setiap gelling agent menghasilkan daya lekat lebih lama, sehingga daya lekat sangat dipengaruhi oleh besarnya konsentrasi yang digunakan pada setiap formula. Hasil pengujian daya lekat untuk sediaan gel hand sanitizer minyak atsiri daun kemangi dengan kosentrasi Carbopol 0,5\%,1\%, dan 1,5\% memiliki daya lekat yang baik yaitu lebih dari 1 detik. Hal ini sesuai dengan persyaratan daya lekat pada sediaan semipadat sebaiknya lebih dari 1 detik (Zats \& Gregory, 1996).

\section{PENUTUP}

Berdasarkan analisa yang telah dilakukan pada sediaan gel hand sanitizer minyak atsiri daun kemangi (Ocimum sanctum L.) dapat disimpulkan bahwa formulasi yang paling optimal dan memenuhi persyaratan sifat fisik dari gelling agent Carbopol 940 adalah (F2) dengan konsentrasi 1\%. Sementara untuk (F1) melebihi standar range daya sebar dan (F3) tidak memenuhi persyaratan $\mathrm{pH}$ untuk sediaan gel hand sanitizer. 


\section{DAFTAR PUSTAKA}

fianti, H. P., dan M. Murrukmihadi, 2015, Pengaruh Variasi Kadar Gelling Agent HPMC terhadap Sifat Fisik Sediaan gel Ekstrak Etanolik Daun Kemangi (Ocimum basilicum L. Forma citratum Back.), Majalah Farmaseutik, Volume 11 Nomor 2, pg 307-315.

Ande, Baktiman, 2014, Skripsi : Pengaruh Penambahan Konsentrasi Carbopol 940 pada Sediaan Sunscreen Gel Ekstrak Temu Giring (Curcuma heyneana Val.) Terhadap Sifat Fisik dan Stabilitas Sediaan dengan Sorbitol sebagai Humectant, Univeritas Sanata Dharma, Yogyakarta.

Ardana, M., Vebry Aeyni., dan Arsyik, I, 2015, Formulasi dan Optimasi Basis Gel HPMC (Hidroxy Propyl Methyl Cellulose) dengan Berbagai Variasi Konsentrasi, J.Top. Pharm. Chem, Volume 3 Nomor 2, pg 102-108.

Garg, A., Aggarwal, D., Garg, S., dan Singla, A.K, 2002, Spreading of Semisolid Formulation, Pharmaceutical Technology, USA, pg 84-104.

Hasyim, N., K.L.Pare., I. Junaid, A. Kurniati, 2012, Formulasi dan uji Efektivitas Gel Luka Bakar Ekstrak Daun Cocor Bebek (Kalanchoe pinnata L.) pada Kelinci (Oryctolagus cuniculus), Majalah Farmasi dan Farmakologi, Volume 16 Nomor 2, pg 89-94.

Larasati, D. A., dan Ety, A., 2016, Efek Potensial Daun Kemangi (Ocimum basilicum L.) sebagai Pemanfaatan Hand Sanitizer, Majority (Medical Journal of Lampung University), Volume 5 Nomor 5, pg 124-128.

Martin, A., Swrbrick, J., Cammarata, A, 1993, Physical Pharmacy, Physical Chemical Principles in The Pharmaceutical Science 2 ed 3, diterjemahkan oleh Yoshita, Universitas Indonesia Press, Jakarta.

Osborne, D.W., 1990, (Eds), Topical Drug Delivery Formulation, Marcell Dekker Inc., New York, pg 381.

Saraung, V., P.V. Yamlean., dan G. Citraningtyas, 2018, Pengaruh Variasi Basis Karbopol dan HPMC Pada Formulasi Gel Ekstrak Etanol Daun Tapak Kuda (Ipomoea pes-caprae (L.) R. Br. Dan Uji Aktivitas Antibakteri Terhadap Staphylococcus aureus, PHARMACON Jurnal Ilmiah Farmasi, Volume 7 Nomor 3 , pg 220-229.

Saryanti, D., dan I. N. Zulfa, 2017, Optimasi Karbopol dan Gliserol sebagai Basis Gel Antiseptik Tangan Ekstrak Etanol Daun Ceremai (Phyllantus acidus (L.) Skeels) dengan Metode Simplex Lattice Design, Journal of Pharmaceutical Science and Clinical Research, 2(1), pg 35-43.

Su'aida, N., Destria, I. S., Mia, F., 2017, Optimasi Sediaan Gel Fraksi Etil Asetat Buah Kasturi (Mangifera casturi Kosterm) dengan Kombinasi Basis CMC-Na dan Carbopol Menggunakan Metode Simplex Lattice Design, JCPS (Journal of Current Pharmaceutical Sciences), Volume 1 Nomor 1, ISSN 2598-2095, pg 19-24. 